\title{
Comparison of Mycobacterium 23S rRNA Sequences by High-Temperature Reverse Transcription and PCR
}

\author{
BENJAMIN B. STONE, ${ }^{*}$ RAYMOND M. NIETUPSKI, $†$ GARY L. BRETON, \\ AND WILLIAM G. WEISBURG \\ GENE-TRAK, Inc., Framingham, Massachusetts 01701
}

\begin{abstract}
We describe a modified rRNA sequence analysis method which we used to determine the phylogenetic relationships among 58 species belonging to the genus Mycobacterium. We combined the sensitivity of the reverse transcriptase PCR for amplifying nanogram amounts of template rRNA material with the elevated extension temperatures used for the thermostable DNA polymerase from Thermus thermophilus. A $70^{\circ} \mathrm{C}$ reverse transcription extension step permitted improved read-through of highly structured rRNA templates from members of the genus Mycobacterium, which have $G+C$ contents of 66 to $71 \mathrm{~mol} \%$. The nucleic acid sequences of the amplified material were then determined by performing thermal cycle sequencing with $\alpha-{ }^{33} \mathrm{P}$-labeled primers, again with extension at $70^{\circ} \mathrm{C}$. Nonspecifically terminated bands were chased by using terminal deoxynucleotidyl transferase. Our method had a template requirement of nanogram amounts or less of purified RNA or 2,000 CFU of intact cells and had sufficient sensitivity so that lyophils obtained from the American Type Culture Collection could be used as source material. Sequences from a 250-nucleotide stretch of the $23 \mathrm{~S}$ rRNA were aligned, and phylogenetic trees were evaluated by using the De Soete distance treeing algorithm and Rhodococcus bronchialis as the outgroup. Our 23S rRNA trees were compared with previously published 16S rRNA trees, including the comprehensive trees developed by the University of Illinois Ribosomal Database Project, and included 15 species not evaluated previously. Most of the groups were in general agreement and were consistent with relationships determined on the basis of biochemical characteristics, but some new relationships were also observed.
\end{abstract}

The genus Mycobacterium contained 56 validated species (18) as of 1991, and recently Shinnick and Good (34) listed 71 species. In addition, there are several subspecies and many trivially named strains. Members of this genus are frequently categorized as being slow growers (more than 7 days is required to see colonies on a plate) or fast growers (less than 7 days is required) (36). Several important human pathogens, including Mycobacterium tuberculosis and Mycobacterium leprae, are members of the slowly growing group, as are a number of opportunistic pathogens (Table 1) (15). In recent reports workers have described methods for using nucleic acid sequences to identify various specific members of the genus $M y$ cobacterium $(4,5,20,21,29,31,37,38)$. However, not all known members of the genus have been examined; the organisms that have not been examined include some strains which have recently been shown to be problematic in probe-based assays $(7,12,14)$.

Our interest in nucleic acid-based probe diagnoses for infectious diseases led us to examine members of the genus Mycobacterium for unique rRNA sequences that can be used to identify potential pathogens. To do this, we needed to evaluate the phylogenetic relationships of pathogenic and environmental strains to develop probes with appropriate specificities. However, several technical difficulties hindered this effort.

One of the technical difficulties that we encountered was the fact that the very low growth rates and low cell yields of many members of the genus Mycobacterium made it difficult to obtain sufficient quantities of purified rRNA for reverse transcriptase (RT) sequencing by the method of Lane et al. (23), as did the BL-3 level containment requirements of several patho-

* Corresponding author. Mailing address: GENE-TRAK, Inc., 31 New York Avenue, Framingham, MA 01701. Phone: (508) 935-1205. Fax: (508) 879-6462.

$\uparrow$ Present address: 6 Cherry St., Millbury, MA 01527. gens. In addition, cloning the ribosomal DNAs (rDNAs) from all 58 species which we studied would have been extremely laborious. Another technical problem was the fact that the high $\mathrm{G}+\mathrm{C}$ contents of mycobacterial genomes frequently inhibited efficient and reliable primer extension by RT through stable secondary structures at $37^{\circ} \mathrm{C}$

In recent years there have been a number of reports describing various methods for improving the method that Lane et al. (23) used for rRNA sequence analysis. The improvements that have been described include separating the labeling step from the termination step (11), altering the concentrations of specific deoxynucleoside triphosphates (40), utilizing low numbers of cells $(27,39)$, sequencing DNA PCR amplicons (6) with an additional $70^{\circ} \mathrm{C}$ extension step (4), and coupling DNA amplification with thermal cycle sequencing $(30,33)$. None of the methods that have been described combined all of the characteristics for developing sequence information desired by us. We sought a method in which small amounts of RNA template material could be used in combination with high extension temperatures. In this paper we describe such a method and the phylogenetic relationships of 58 members of the genus Mycobacterium based on a 250 -nucleotide, variable region of the $23 \mathrm{~S}$ rRNA subunit. The organisms which we used included 17 species which have not been included yet on the complete $16 \mathrm{~S}$ rRNA tree developed by the Ribosomal Database Project (RDP) at the University of Illinois; 15 of these species have not had their $16 \mathrm{~S}$ rRNA sequences evaluated in a phylogenetic context yet.

\section{MATERIALS AND METHODS}

Growth of bacterial strains. Organisms (Table 1) were grown on Middlebrook $7 \mathrm{H10}$ agar. Cell pellets or lyophils were processed by shaking them with zirconium beads and phenol as described previously (3).

Nucleic acid purification. RNA was purified from cell lysates (3) through a cesium trifluoroacetic acid gradient as described previously (3). When DNA was used as the template material, it was cloned from PCR-amplified ribosomal 
TABLE 1. Strains used in this study

\begin{tabular}{|c|c|c|c|c|}
\hline Species & Strain $^{a}$ & Growth rate $^{b}$ & Template & GenBank accession no. \\
\hline \multicolumn{5}{|l|}{ Strict pathogens ${ }^{d}$} \\
\hline Mycobacterium africanum ${ }^{e}$ & ATCC $25420^{\mathrm{T}}$ & S & $R / D$ & U24502 \\
\hline Mycobacterium asiaticum & ATCC $25276^{\mathrm{T}}$ & $\mathrm{S}$ & $\mathrm{R}$ & U24505 \\
\hline Mycobacterium bovis & ATCC 35745 & $\mathrm{~S}$ & $\mathrm{D}$ & U24509 \\
\hline Mycobacterium haemophilum ${ }^{e}$ & GT3804 & $\mathrm{S}$ & $\mathrm{R}$ & $\mathrm{U} 24526$ \\
\hline Mycobacterium leprae & & $\mathrm{S}^{f}$ & & X56657 \\
\hline Mycobacterium malmoense & ATCC $29571^{\mathrm{T}}$ & $\mathrm{S}$ & $\mathrm{R}$ & U24531 \\
\hline Mycobacterium shimoideie & ATCC $27962^{\mathrm{T}}$ & $\mathrm{S}$ & $\mathrm{R}$ & $\mathrm{U} 24547$ \\
\hline Mycobacterium simiae & ATCC $25275^{\mathrm{T}}$ & $\mathrm{S}$ & $\mathrm{R}$ & U24548 \\
\hline Mycobacterium tuberculosis & H37Ra $(=$ ATCC 25177$)$ & $\mathrm{s}$ & $R / D$ & U24555 \\
\hline Mycobacterium ulcerans ${ }^{e}$ & GT4380 & $\mathrm{S}$ & $\mathrm{R}$ & U24556 \\
\hline \multicolumn{5}{|l|}{ Opportunistic pathogens } \\
\hline Mycobacterium avium & GT3246 & $\mathrm{S}$ & $\mathrm{D}$ & U24508 \\
\hline Mycobacterium celatum ${ }^{e}$ & ATCC $51131^{\mathrm{T}}$ & $\mathrm{S}$ & $R / D$ & U24510 \\
\hline Mycobacterium chelonae & GT3248 & $\mathrm{F}$ & $\mathrm{R}$ & $\mathrm{U} 24511$ \\
\hline Mycobacterium farcinogenes & ATCC $35753^{\mathrm{T}}$ & S & $\mathrm{R}$ & $\mathrm{U} 24517$ \\
\hline Mycobacterium fortuitum & ATCC $6841^{\mathrm{T}}$ & $\mathrm{F}$ & $R / D$ & U24519 \\
\hline Mycobacterium genavense & GT5011 & $\mathrm{S}$ & $\mathrm{R} / \mathrm{D}$ & U24523 \\
\hline Mycobacterium intracellulare & ATCC $13950^{T}$ & $\mathrm{~S}$ & $\mathrm{D}$ & U24527 \\
\hline Mycobacterium kansasii & ATCC $12478^{\mathrm{T}}$ & $\mathrm{s}$ & $\mathrm{D}$ & $\mathrm{U} 24528$ \\
\hline Mycobacterium marinum & ATCC $927^{\mathrm{T}}$ & $\mathrm{s}$ & $\mathrm{R}$ & $\mathrm{U} 24532$ \\
\hline Mycobacterium microti & ATCC 11152 & $\mathrm{~s}$ & $\mathrm{R}$ & U24533 \\
\hline Mycobacterium paratuberculosis ${ }^{g}$ & ATCC 19689 & $\mathrm{~s}$ & $\mathrm{R}$ & $\mathrm{U} 24539$ \\
\hline Mycobacterium porcinum ${ }^{e}$ & ATCC $33776^{\mathrm{T}}$ & $\mathrm{F}$ & $\mathrm{R}$ & $\mathrm{U} 24541$ \\
\hline Mycobacterium scrofulaceum & ATCC $19981^{\mathrm{T}}$ & $S$ & $\mathrm{D}$ & $\mathrm{U} 24545$ \\
\hline Mycobacterium senegalense & ATCC $35796^{\mathrm{T}}$ & $\mathrm{F}$ & $\mathrm{R}$ & $\mathrm{U} 24546$ \\
\hline Mycobacterium szulgai & ATCC $35799^{\mathrm{T}}$ & $\mathrm{S}$ & $\mathrm{R}$ & U24551 \\
\hline Mycobacterium xenopi & ATCC $19250^{\mathrm{T}}$ & $\mathrm{s}$ & $\mathrm{R}$ & U24558 \\
\hline \multicolumn{5}{|l|}{ Rare, potential pathogens } \\
\hline Mycobacterium flavescens & ATCC $14474^{\mathrm{T}}$ & $\mathrm{F}$ & $\mathrm{R}$ & $\mathrm{U} 24518$ \\
\hline Mycobacterium gordonae & ATCC 35756 & $\mathrm{~S}$ & $\mathrm{R} / \mathrm{D}$ & $\mathrm{U} 24525$ \\
\hline "Mycobacterium lactis"e,h & ATCC 27356 & & $\mathrm{R}$ & U24530 \\
\hline Mycobacterium lepraemurium ${ }^{e g}$ & ATCC 35779 & $\mathrm{~s}$ & & $\mathrm{ND}^{i}$ \\
\hline Mycobacterium neoaurum & ATCC $27595^{\mathrm{T}}$ & $\mathrm{F}$ & $\mathrm{R}$ & U24535 \\
\hline Mycobacterium smegmatis & ATCC 14468 & $\mathrm{~F}$ & $\mathrm{R}$ & $\mathrm{U} 24549$ \\
\hline Mycobacterium thermoresistibile & ATCC $19527^{T}$ & $\mathrm{~F}$ & $\mathrm{R}$ & $\mathrm{U} 24553$ \\
\hline \multicolumn{5}{|c|}{ Nonpathogenic environmental mycobacteria } \\
\hline Mycobacterium agrie & ATCC $27406^{\mathrm{T}}$ & $\mathrm{F}$ & $\mathrm{R}$ & $\mathrm{U} 24503$ \\
\hline Mycobacterium aichiense & ATCC $27280^{\mathrm{T}}$ & $\mathrm{F}$ & $\mathrm{R}$ & $\mathrm{U} 24504$ \\
\hline Mycobacterium aurum & ATCC $23366^{\mathrm{T}}$ & $\mathrm{F}$ & $\mathrm{R}$ & $\mathrm{U} 24506$ \\
\hline Mycobacterium austroafricanum ${ }^{e}$ & ATCC $33464^{\mathrm{T}}$ & $\mathrm{F}$ & $\mathrm{R}$ & $\mathrm{U} 24507$ \\
\hline Mycobacterium chitae & ATCC $19627^{\mathrm{T}}$ & $\mathrm{F}$ & $\mathrm{D}$ & $\mathrm{U} 24512$ \\
\hline Mycobacterium chubuense & ATCC $27278^{\mathrm{T}}$ & $\mathrm{F}$ & $\mathrm{R}$ & $\mathrm{U} 24513$ \\
\hline Mycobacterium diernhoferi & ATCC 19343 & $\mathrm{~F}$ & $\mathrm{R}$ & U24514 \\
\hline Mycobacterium duvalie & ATCC $43910^{\mathrm{T}}$ & $\mathrm{F}$ & $\mathrm{R}$ & $\mathrm{U} 24515$ \\
\hline Mycobacterium fallax & ATCC $35219^{\mathrm{T}}$ & $\mathrm{F}$ & $\mathrm{R}$ & $\mathrm{U} 24516$ \\
\hline Mycobacterium gadium & ATCC $27726^{\mathrm{T}}$ & $\mathrm{F}$ & $\mathrm{R}$ & $\mathrm{U} 24520$ \\
\hline "Mycobacterium gallinarum"e,h & ATCC 19710 & & $\mathrm{R}$ & U24521 \\
\hline Mycobacterium gastri & ATCC $15754^{\mathrm{T}}$ & S & $\mathrm{R} / \mathrm{D}$ & $\mathrm{U} 24522$ \\
\hline Mycobacterium gilvum & ATCC $43909^{\mathrm{T}}$ & $\mathrm{F}$ & $\mathrm{R}$ & $\mathrm{U} 24524$ \\
\hline
\end{tabular}

Continued on following page

genes by using the method of Weisburg et al. (41) and 23S rDNA eubacterial primers derived from the study of Lane (22). To determine the sensitivity of the amplification procedure, quantified cells were extracted by the procedure of Barns et al. (3). The supernatant from the phenol extractions was ethanol precipitated by using yeast tRNA as the carrier. The pellets were redissolved in $100 \mu$ l of $10 \mathrm{mM}$ Tris ( $\mathrm{pH}$ 8)-1 mM EDTA buffer, and $1 \mu \mathrm{l}$ was used as template material for $\mathrm{r} T$ th $\mathrm{RT}$ amplification.

Nucleic acid amplification. For reverse transcription and subsequent PCR we followed the recommendations of Perkin-Elmer-Cetus, Norwalk, Conn., and used the rTth DNA polymerase and reagents in a GeneAmp thermostable rTth RT RNA PCR kit (Perkin-Elmer-Cetus). Reverse primer 3284 (Table 2) was annealed at $70^{\circ} \mathrm{C}$ for $10 \mathrm{~min}$ in the presence of $1 \mathrm{mM} \mathrm{MnCl}$. Following chelation with EGTA [ethylene glycol-bis ( $\beta$-aminoethyl ether)- $N, N, N^{\prime}, N^{\prime}$-tetraacetic acid], the DNA was amplified for 40 cycles with denaturation at $94^{\circ} \mathrm{C}$ for $20 \mathrm{~s}$ and annealing with forward primer 3415 and extension at $70^{\circ} \mathrm{C}$ for $20 \mathrm{~s}$. The following three species required slightly less stringent annealing conditions $\left(65^{\circ} \mathrm{C}\right): \mathrm{Myco}-$ bacterium gilvum, Mycobacterium smegmatis, and Mycobacterium rhodesiae. Am- plicons were purified from buffer and primers by using Ultra Free-MC 30,000 mw spin filters (Millipore, Bedford, Mass.)

Nucleic acid sequencing. The primers used for amplification and sequencing (Table 2) were designed to hybridize primarily to high-G+C-content grampositive organisms and to be stable for annealing at $70^{\circ} \mathrm{C}$. Primer 3415 and reverse primer 3284 generated a 369-bp amplicon from M. tuberculosis. For thermal cycle sequencing of linear, double-stranded amplicons we used $\alpha{ }^{33} \mathrm{P}$ labeled primers, as well as the reagents and protocols described in an AmpliTaq cycle sequencing kit (Perkin-Elmer-Cetus). Most ambiguities were resolved by sequencing the opposite strand. Nondideoxy-terminated pause sites were alleviated with a terminal deoxynucleotidyl transferase chase at $37^{\circ} \mathrm{C}$ for $30 \mathrm{~min}$ as described previously (22). The sequences of DNA clones were determined by using a Sequenase kit (U.S. Biochemicals, Cleveland, Ohio).

Nucleic acid sequence analysis. Sequences (Escherichia coli positions 519 to 729) were manually aligned with a VAX minicomputer by using the Olsen sequence editor (28) and were printed by using a MegAlign (version 3.02) package obtained from DNASTAR, Madison, Wis. Two hypervariable stem-loop 
TABLE $1-$ Continued

\begin{tabular}{|c|c|c|c|c|}
\hline Species & Strain $^{a}$ & Growth rate ${ }^{h}$ & Template $^{c}$ & GenBank accession no. \\
\hline Mycobacterium komossense & ATCC $33013^{\mathrm{T}}$ & $\mathrm{F}$ & $\mathrm{R}$ & U24529 \\
\hline Mycobacterium moriokaense $e^{e}$ & ATCC $43059^{T}$ & $\mathrm{~F}$ & $\mathrm{R}$ & $\mathrm{U} 24534$ \\
\hline Mycobacterium nonchromogenicum & AТCC $19530^{\mathrm{T}}$ & $\mathrm{S}$ & $\mathrm{R}$ & $\mathrm{U} 24536$ \\
\hline Mycobacterium obuense & ATCC $27023^{\mathrm{T}}$ & $\mathrm{F}$ & $\mathbf{R}$ & $\mathrm{U} 24537$ \\
\hline Mycobacterium parafortuitum ${ }^{e}$ & ATCC $19686^{\mathrm{T}}$ & $\mathrm{F}$ & $\mathrm{R}$ & $\mathrm{U} 24538$ \\
\hline Mycobacterium phlei & ATCC $11758^{\mathrm{T}}$ & $\mathrm{F}$ & $\mathrm{R}$ & $\mathrm{U} 24540$ \\
\hline Mycobacterium poriferae $e^{e}$ & ATCC $35087^{\mathrm{T}}$ & $\mathrm{F}$ & $\mathrm{R}$ & $\mathrm{U} 24542$ \\
\hline Mycobacterium pulveris ${ }^{e}$ & $\operatorname{ATCC} 35154^{\mathrm{T}}$ & $\mathrm{F}$ & $\mathrm{R}$ & $\mathrm{U} 24543$ \\
\hline Mycobacterium rhodesiae ${ }^{e}$ & ATCC $27024^{\mathrm{T}}$ & $\mathrm{F}$ & $\mathrm{R}$ & $\mathrm{U} 24544$ \\
\hline Mycobacterium sphagni & ATCC $33027^{\mathbf{T}}$ & $\mathrm{F}$ & $\mathrm{R}$ & $\mathrm{U} 24550$ \\
\hline Mycobacterium terrae & GT3247 & $\mathrm{S}$ & $\mathrm{R}$ & $\mathrm{U} 24552$ \\
\hline Mycobacterium tokaiense $e^{e}$ & ATCC $27282^{\mathrm{T}}$ & $\mathrm{F}$ & $\mathrm{R}$ & $\mathrm{U} 24554$ \\
\hline Mycobacterium triviale & ATCC $23292^{\mathrm{T}}$ & $\mathrm{S}$ & & ND \\
\hline Mycobacterium vaccae & AТCC $15483^{\mathrm{T}}$ & $\mathrm{F}$ & $\mathrm{R}$ & $\mathrm{U} 24557$ \\
\hline \multicolumn{5}{|l|}{ Nonmycobacteria } \\
\hline Corynebacterium glutamicum & ATCC $13032^{\mathrm{T}}$ & & $\mathrm{R}$ & \\
\hline Micrococcus luteus & ATCC 381 & & $\mathrm{R}$ & \\
\hline Rhodococcus bronchialis & ATCC $25592^{\mathrm{T}}$ & & $\mathrm{R} / \mathrm{D}$ & $\mathrm{U} 24559$ \\
\hline
\end{tabular}

a ATCC, American Type Culture Collection; GT, GENE-TRAK Collection.

${ }^{b} \mathrm{~S}$, slow; F, fast.

${ }^{c} \mathrm{R} / \mathrm{D}, \mathrm{RNA}$ or DNA; R, RNA; D, DNA.

¿ Pathogens classified as described by Good (15).

${ }^{e}$ Not included on the RDP 16S rRNA tree.

${ }^{f} M$. leprae is a slowly growing obligately intracellular parasite.

${ }^{g}$ Lyophil obtained from the American Type Culture Collection.

${ }^{h}$ Not a valid species.

i ND, not determined.

structures occur in this region, and these sequences were aligned by determining homologous structures as base-complementary stems. The secondary structure of $M$. leprae (16) was used as the basis for these alignments. A sequence mask was used to remove ambiguously aligned positions from the analysis. Phylogenetic trees were developed in the Genetic Data Environment with a SUN SPARCstation by using the De Soete distance treeing algorithm (10). A 16S rRNA tree for the genus Mycobacterium was provided by the RDP $(23 \mathrm{a}, 24)$.

Nucleotide sequence accession numbers. The GenBank accession numbers of the 23S rRNA sequences shown in Fig. 1 are given in Table 1.

\section{RESULTS}

Sensitivity of RT amplification. Natural total RNAs were prepared from various strains, including $M$. tuberculosis H37Ra (avirulent). We assumed that one-half of the mass of each total RNA was $23 \mathrm{~S}$ rRNA. This material was serially diluted, and $1-\mu l$ aliquots were used as templates for RT PCR. We routinely detected at least $1 \mathrm{ng}$ in each experiment when we used various sources, including Corynebacterium glutamicum, Micrococcus luteus, and Rhodococcus bronchialis (data not shown). A maximum level of sensitivity of $10 \mathrm{pg}$ was observed in the RT PCR with $M$. tuberculosis (data not shown); this represented between $10^{6}$ and $10^{7}$ initial rRNA template molecules. DNA PCR in which we used AmpliTaq DNA polymerase (Perkin-Elmer-Cetus) and primers 3415 and 3284 (Table 2) were performed with these same samples to demonstrate that the RNA, not contamination by trace amounts of DNA, was the template material. We detected no products by ethidium bromide staining following agarose gel electrophoresis (data not shown).

We were concerned about the relatively poor sensitivity in our experiments compared with the data of Meyers and Gelfand (26), who observed levels of sensitivity between 100 and 1,000 copies with transcribed RNA. Synthetic transcripts of a clone of the $5^{\prime}$ one-half of the 23S rRNA gene from $M$. tuberculosis H37Ra (avirulent) were prepared by using T7 RNA polymerase (Promega, Madison, Wis.), and the amounts of these transcripts were determined by measuring the $A_{260}$. Next, serial dilutions were prepared, and $1-\mu l$ aliquots were used as template material. We found that the level of sensitivity obtained with the synthetic RNA was at least 3 orders of magnitude higher than the level of sensitivity obtained with the natural material (data not shown). Since the transcript included only about 1,600 nucleotides, 1 fg represented $10^{3}$ molecules. These results more closely approached the results of Meyers and Gelfand (26).

There are several possible reasons for the difference in sensitivity between the natural and synthetic rRNAs. Posttranscriptional modifications of the natural rRNA, such as methylation, could have inhibited efficient copying by the polymerase. It is also possible that the secondary and/or tertiary structure of the full-length natural rRNA was more stable, which could have further impeded copying. The synthetic transcript included only the first one-half of the $23 \mathrm{~S}$ rRNA molecule.

TABLE 2. Amplification and sequencing primers targeted to high-G+C-content gram-positive eubacteria

\begin{tabular}{lcccl}
\hline Primer & $\begin{array}{c}\text { No. of } \\
\text { nucleotides }\end{array}$ & $\begin{array}{c}\text { G }+\mathrm{C} \text { content } \\
(\mathrm{mol} \%)\end{array}$ & $\begin{array}{c}\text { E. coli } \\
\text { positions }\end{array}$ & Sequence $\left(5^{\prime}\right.$ to $\left.3^{\prime}\right)$ \\
\hline 3415 & 32 & 53 & $457-488$ & AGTACCGTGA GGGAAAGGTG AAAAGTACCC CG \\
3359 & 27 & 48 & $553-579$ & GTGATGGCGT GCCTTTTGWA GAATGAG \\
3429 & 27 & 56 & $751-725$ & TTTCAACCTA AGTGGGTTCG GGCCTCC \\
3284 & 22 & 59 & $791-770$ & GATTGGCCTT TCACCCCTAC CC \\
\hline
\end{tabular}



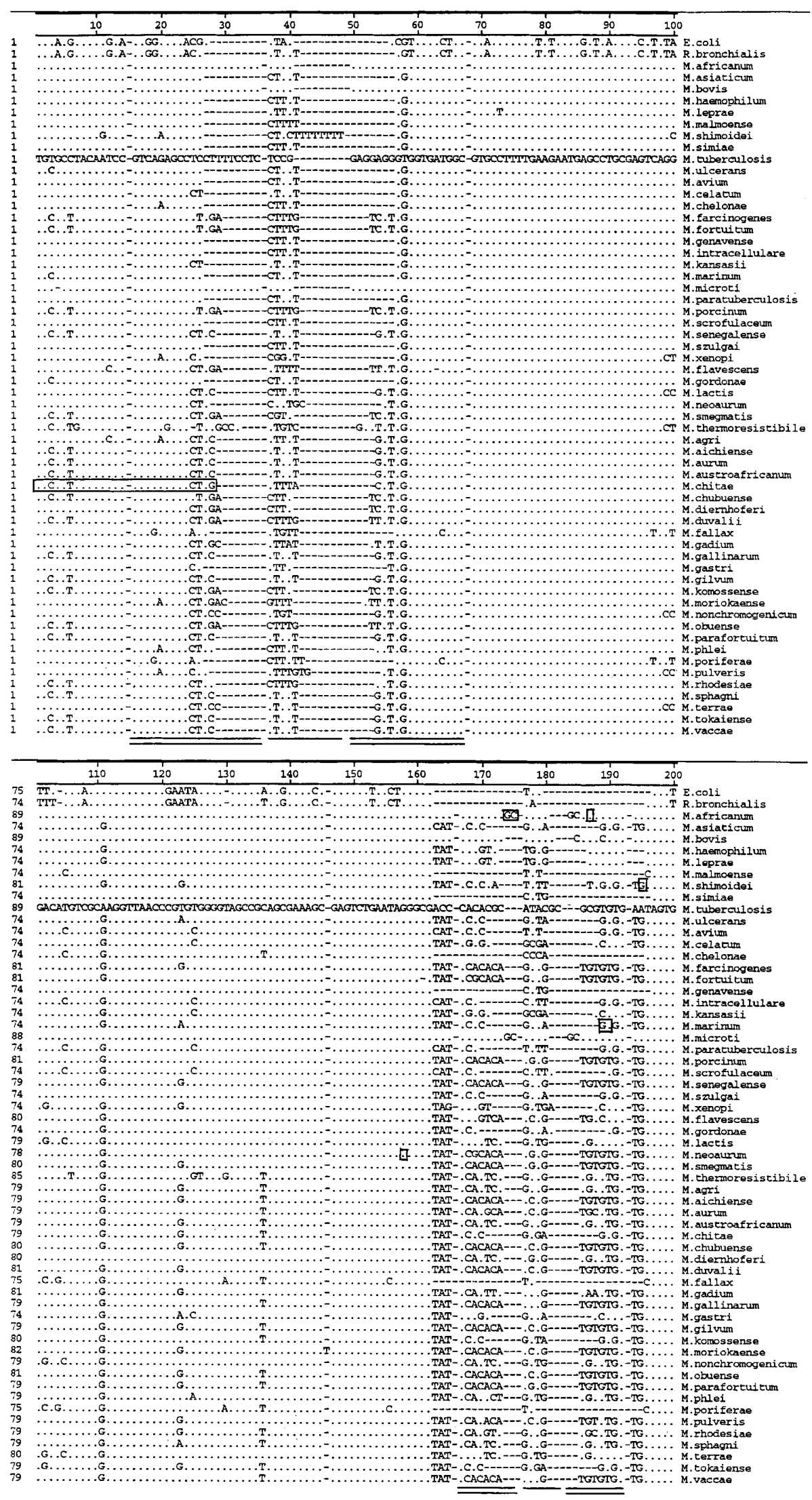


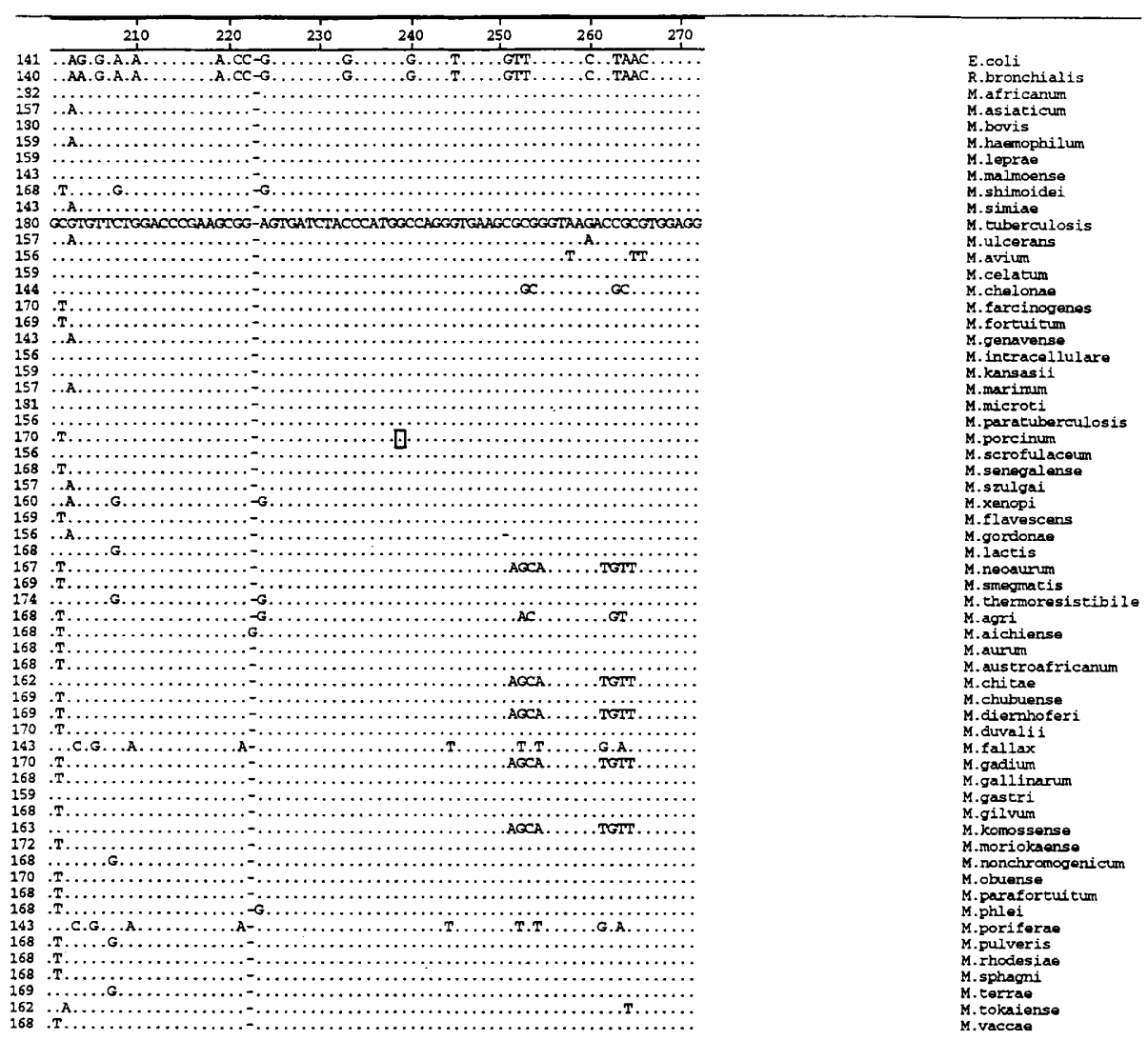

FIG. 1. Alignment of $23 \mathrm{~S}$ rRNA sequences. The region shown includes homologous $E$. coli positions 519 through 729 . All of the sequences are shown as the DNA form ( $\mathrm{T}$ in place of $\mathrm{U}$ ). Dots represent sequence nucleotides which correspond to nucleotides in the $M$. tuberculosis sequence. Dashes are included for alignment purposes. The residues enclosed in boxes are residues that were determined with only one primer and one strand. Table 1 shows the sources of sequences and the nature of the template material (RNA or DNA). The core loop structure was derived from $M$. leprae (16). Stem regions are underlined with two lines; loop regions are underlined with one line.

We wanted to demonstrate the utility of our technique for amplifying rRNA fragments from very low yields of whole cells. We used $R$. bronchialis as a model instead of mycobacteria to eliminate the need for BL-3 containment during processing. Our results revealed a level of sensitivity of about $2,000 \mathrm{CFU}$ (data not shown). Assuming that there are approximately $1,00023 \mathrm{~S}$ rRNA targets per CFU (1), this finding is consistent with the presence of $10^{6}$ to $10^{7}$ molecules of purified natural rRNA. These values do not account for possible losses during the extraction procedure and therefore are probably underestimates of the true level of sensitivity. Nevertheless, these values are useful for demonstrating the limits for potential screening programs. Single colonies should provide adequate material for amplification. We were able to amplify material from lyophils of Mycobacterium paratuberculosis.

Sequence analysis. The mycobacterial $23 \mathrm{~S}$ rRNA regions homologous to $E$. coli positions 519 to 729 are shown in Fig. 1. These regions were used to develop the phylogenetic trees shown in Fig. 2. In the detailed overview analysis (Fig. 2A) we included 17 species that have not been included yet on the $16 \mathrm{~S}$ rRNA tree available from the RDP at the University of Illinois. Two of these species, Mycobacterium celatum (34) and Mycobacterium africanum (13), have been placed phylogenetically by other workers. Figure $2 \mathrm{~B}$ shows the positions of a selection of species extracted from the whole group and reanalyzed to clarify the main groups, as well as improve the general reliability of the results. For the most part the groups of species on these trees are similar to the groups on the rRNA 16S rRNA tree. Some specific differences are discussed below.

Mycobacterium chitae ATCC1962 $7^{\mathrm{T}}(\mathrm{T}=$ type strain) clustered in the genus Mycobacterium near Mycobacterium komossense, as found on the 16S rRNA tree obtained from the RDP and as described in a reexamination of this strain by Pitulle et al. (29). This finding is not consistent with the data of Stahl and Urbance (36), who found that $M$. chitae is less closely related to the genus Mycobacterium than Rhodococcus equi is. We found that Mycobacterium fallax and Mycobacterium poriferae were separated from the main group of the genus Mycobacterium, whereas on the $16 \mathrm{~S}$ rRNA trees $M$. fallax clusters with $M$. chitae and Mycobacterium gadium.

Figure $2 \mathrm{C}$ shows the results of an analysis of the fast-growing species, in which $M$. tuberculosis was used as the outgroup. The large cluster from $M$. gilvum to Mycobacterium phlei was quite similar to a large group on the RDP 16S rRNA tree. Mycobacterium farcinogenes was excluded from this analysis because of its slow growth rate, but both on the tree shown in Fig. 2A and on the 16S rRNA trees this organism was placed in this cluster. We found that $M$. gadium grouped with Mycobacterium diernhoferi and Mycobacterium neoaurum and is closely related to $M$. chitae. As noted above, on the RDP $16 \mathrm{~S}$ rRNA tree $M$. fallax clusters close to these species, whereas on our tree it clustered separately, along with $M$. poriferae.

Figure 2D shows the results of an analysis of the slowly growing species, in which $M$. smegmatis was used as the out- 


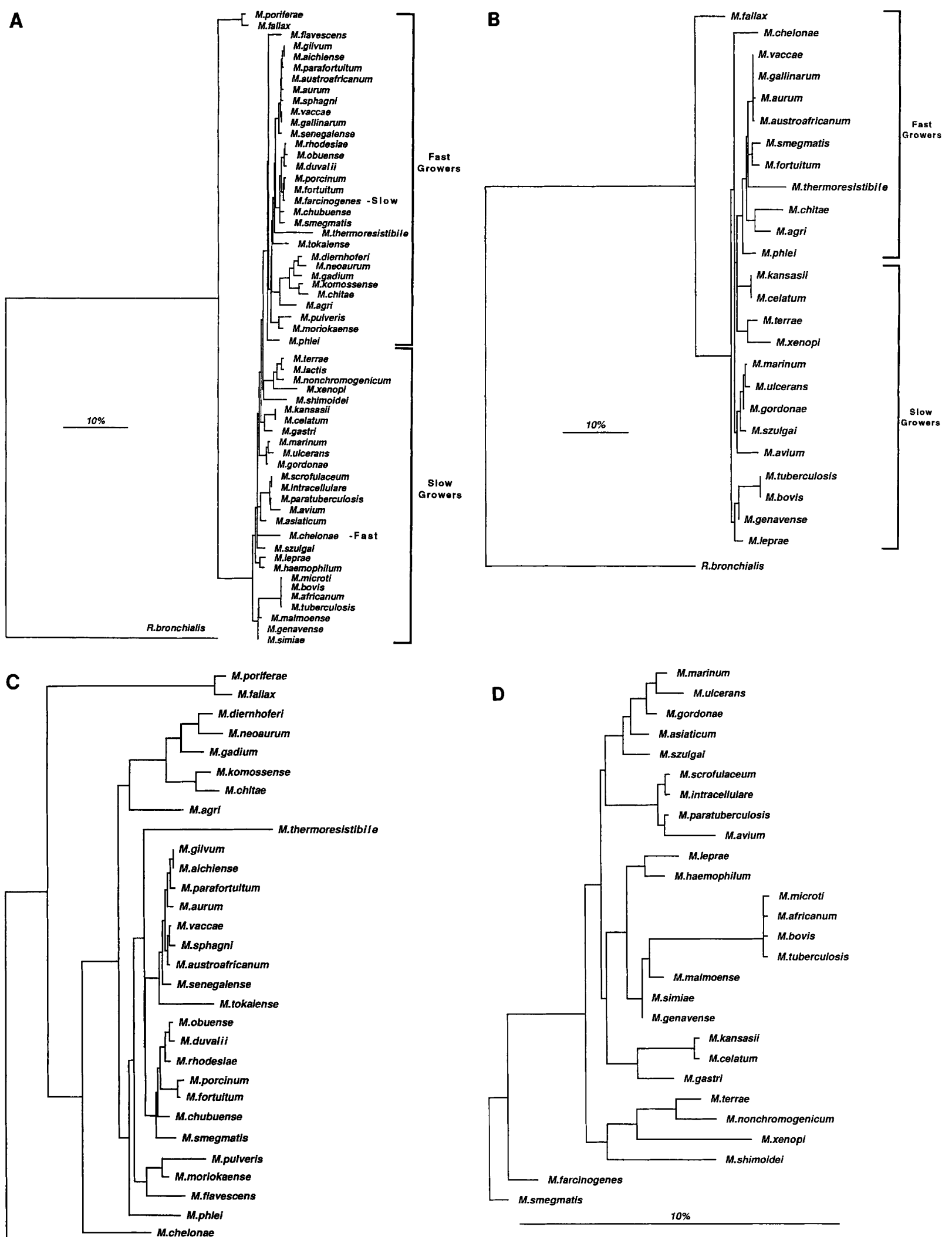

FIG. 2. Phylogenetic relationships based on partial 23S rRNA sequences. (A). Overview of 58 species of the genus Mycobacterium. Note that "Mycobacterium lactis" and "Mycobacterium gallinarum" are not officially recognized species. $R$. bronchialis was used as the outgroup. (B). Selected overview of the genus Mycobacterium. Reducing the number of species in the tree should have improved the general reliability of the relationships. (C). Selected subgroup of fast growers. M. tuberculosis was used as the outgroup. (D). Selected subgroup of slow growers. M. smegmatis was used as the outgroup. 
group. Mycobacterium marinum clustered with Mycobacterium gordonae and close to Mycobacterium asiaticum and Mycobacterium szulgai. On the $16 \mathrm{~S}$ rRNA trees $M$. marinum is closely related to $M$. tuberculosis. The recently described organism Mycobacterium genavense is very closely related to Mycobacterium simiae, as found on the RDP $16 \mathrm{~S}$ rRNA tree and as determined by a mycolic acid profile analysis (9). M. celatum is identical to Mycobacterium kansasii, a finding which is inconsistent with the phenotypic placement of these organisms as a slowly growing nonphotochromogen and a slowly growing photochromogen, respectively (34). Mycobacterium haemophilum, whose phylogenetic position has not been described, exhibited a high level of $23 \mathrm{~S}$ rRNA sequence similarity to $M$. leprae despite many dissimilar phenetic traits (34).

\section{DISCUSSION}

Method. The method described above was a synthesis of the following two established techniques for molecular analysis of RNA sequences: (i) reverse transcription coupled to PCR amplification in which the recombinant DNA polymerase from Thermus thermophilus is used, and (ii) thermal cycle sequencing of the resulting amplicons to avoid many of the problems associated with sequencing linear, double-stranded templates. In this method ${ }^{33} \mathrm{P}$-end-labeled sequencing primers are used, and amplicons are rapidly separated from amplification primers by using microcentrifuge spin filters. Thus, there is no requirement for gel purification (2), exonuclease digestion (19, 32 ), biotin capture (25), cold temperature "snap" annealing (8), or separate asymmetric amplification of each strand (17). Our method has several distinct advantages which we used for phylogenetic analysis of the vast majority of species in the genus Mycobacterium (currently 69 type strains are listed by the American Type Culture Collection).

Very small amounts of template material are required for the method described in this paper. Routinely, less than $1 \mathrm{ng}$ of total RNA (as little as $10 \mathrm{pg}$ was used in this study) or fewer than $10^{4}$ cells are needed to generate amplicons, compared with the 4 to $10 \mu \mathrm{g}$ of RNA needed for avian myeloblastosis virus-based RT sequencing (23). This is an improvement in sensitivity of at least 3 to 4 (up to 6) orders of magnitude. Compared with the sensitivity of PCR amplification of rDNA genes $(5,6)$, this is not a step forward. However, we initially targeted RNA (instead of the coding rDNA) because we assumed that the natural copy number (at least 1,000 copies per CFU for $M$. tuberculosis [1]) would improve the sensitivity of the amplification technique. This assumption was investigated experimentally as described above. Furthermore, we were slightly concerned about sequence variation in chromosomal rDNA genes in those species (presumably including the fast growers) that contain more than one copy. Using the rRNA molecules directly provided sequences from the functional final gene products.

A high temperature during the annealing and extension step permitted improved read-through of stable secondary structures, whereas avian myeloblastosis virus RT is used at $37^{\circ} \mathrm{C}$. This is particularly important for high-G+C-content organisms. Our experience with avian myeloblastosis virus RT showed that our technique resulted in significant improvement in the ability to read sequence information. Despite this, some secondary structures were still a problem during sequencing extension with members of the genus Mycobacterium, even at $70^{\circ} \mathrm{C}$. We determined that these structures were not gel artifacts since they could be chased away with terminal deoxynucleotidyl transferase.

Sequencing two strands results in improved resolution in denaturing gels because of different specific secondary structures that form with different primers. Avian myeloblastosis virus RT sequencing offers fewer options for checking sequence information. However, it is important to note that the sequence information originates from a single strand, compared with material cloned from PCR amplification preparations.

While the latter approach is an option, it is more time consuming. In addition, because at least 1,000 template molecules are required, the method described in this paper shares the advantage of direct PCR amplification and subsequent thermal cycle sequencing of rDNA genes (6) in that single misincorporations should not detectably affect the sequence information. This can be a problem with material cloned from PCR amplification preparations.

Phylogenetic relationships. The data presented in this paper place for the first time 15 members of the genus Mycobacterium in a phylogenetic context based on rRNA sequence information. Several of these organisms, including $M$. haemophilum, Mycobacterium shimoidei, and Mycobacterium ulcerans, are considered pathogenic for humans. We compared our results with the comprehensive overview provided by the 16S rRNA phylogenetic tree of the RDP, as well as with the results of specific analyses described previously $(13,29,31,36)$. For the most part, our results corroborate the 16S rRNA tree data, although there are some exceptions.

It is important to note that a true phylogeny probably will not be derived from a single character, such as a fragment of the 23S rRNA sequence. A polyphasic approach (35) will help even out the deficiencies of using specific traits (e.g., molecular size, stability, "evolutionary clock"). Therefore, our 23S rRNA data are not intended to be used to rewrite the phylogeny of the genus Mycobacterium, but rather complement the data obtained previously. In the case of the 15 species which we studied whose 16S rRNA sequences have not been aligned yet, phenetic traits still should be given significant weight.

Stahl and Urbance (36) and Rogall et al. (31) found that the growth rates of species (slowly growing versus fast growing) appeared to be phylogenetically conserved on the basis of $16 \mathrm{~S}$ rRNA sequence data. Figures $2 \mathrm{~A}$ and $\mathrm{B}$ show that all of the organisms except two can be clustered on the basis of growth rates. Initially, $M$. chelonae (a fast grower) was grouped with the slowly growing species (Fig. 2A). However, when we examined a subset of the members of the genus (Fig. 2B), $M$. chelonae was placed in the fast-growing species cluster. This change in position probably resulted from the limited sequence examined (29).

$M$. farcinogenes, a slowly growing species, clustered with the fast growers, close to Mycobacterium fortuitum (Fig. 2A) and in a subcluster adjacent to Mycobacterium senegalense. This position is very similar to the position determined on the basis of $16 \mathrm{~S}$ rRNA sequences (29). Although the taxonomic position of this species has not been determined by using other phenetic traits, the results of DNA hybridization studies place it near $M$. senegalense (34). Assuming that the extracted and reanalyzed positions of $M$. chelonae and its fellow fast-growing species in Fig. 2B are correct, this is the only example of a contradiction with the slow-fast phylogenetic split $(31,36)$. The results of several independent approaches (16S rRNA, 23S rRNA, DNA hybridization) have placed $M$. farcinogenes with the fast growers, and slow growth appears to be a recently acquired trait (29). It is possible that the loss of rapid growth potential in $M$. farcinogenes has been acquired independently.

The position of $M$. chitae ATCC19627 $7^{\mathrm{T}}$ which we determined in this study is similar to the position of this organism on the RDP 16S rRNA tree and the position determined by Pitulle et al. (29). Pitulle et al. reexamined the $16 \mathrm{~S}$ rRNA 
sequence of this strain and obtained dramatically different results than Stahl and Urbance obtained (36). Both groups of authors recommended a comprehensive reexamination of the authenticity of this strain. Since the phenetic traits and mycolic acid composition of $M$. chitae still place it in the genus Mycobacterium (18), there may have been a problem with the specific culture used by Stahl and Urbance (36).

The identical 23S rRNA sequences of $M$. celatum and $M$. kansasii, like the identical 16S rRNA sequences of $M$. gastri and $M$. kansasii, provide another example of the limitations of relying on a single trait to place species in groups. While both $M$. celatum and $M$. kansasii are opportunistic pathogens in immunocompromised hosts, they belong to different Runyon groups (groups III [nonphotochromogens] and I [photochromogens], respectively) and have different biochemical test profiles (34). Along the same lines, in this study $M$. haemophilum and $M$. leprae clustered closely, although they clearly are quite different bacteria (34). $M$. leprae, an obligately intracellular pathogen, clusters close to (RDP) or between (34) the $M$. tuberculosis complex and the Mycobacterium avium complex. Although $M$. haemophilum, a nonphotochromogen, is similar to the $M$. avium complex in several biochemical characteristics, it has a distinctive mycolic acid profile; furthermore, it requires complexed iron for growth and can be cultured in vitro. Thus, the 23S rRNA sequence similarities belie important phenetic differences, which should again promote caution in the development of a true phylogeny.

Another difference is the branching of $M$. fallax and $M$. poriferae away from the main line of the genus. While the $23 \mathrm{~S}$ rRNA sequences exhibited the deepest split within the genus in this study, the $16 \mathrm{~S}$ rRNA trees $(29,34)$ also exhibit a reasonably deep branch point for $M$. fallax (until now $M$. poriferae has not been placed taxonomically). The true evolutionary significance of these differences may be muted by some of the limitations inherent in using this data set.

First, the sequences are not totally nonbiased for selection. Note the differences in the $M$. tuberculosis complex sequences, the $M$. avium complex sequences, and the sequences of other species. This $23 \mathrm{~S}$ rRNA region was chosen because of probe development considerations, as well as method development and phylogenetic evaluation considerations. Therefore, this region was not randomly chosen on the basis of conserved structures but rather was chosen on the basis of hypervariable regions.

Second, as noted above, only about 250 nucleotides were evaluated, and fewer positions in an alignment are never as good as as many as possible. Thus, the phylogenetic trees which we obtained are not completely robust. Future changes in groups and membership are likely when more sequence information becomes available.

Finally, short branch lengths can be questionable, as discussed by Pitulle et al. (29). Short internodal distances are less predictive than long internodal distances. This could explain the variable position of $M$. chelonae depending upon the subset of species with which it is analyzed. Of course, efforts to neatly categorize the species highlight the anthropocentric nature of the fast-versus-slow division, and it may be more appropriate to consider some species phylogenetically intermediate between the two groups.

\section{ACKNOWLEDGMENTS}

We thank Debra Buxton, Annette Hendricks, Joseph Murphy, and William O'Brien for culturing strains and Seth Cohen and David Lane for critically reviewing the manuscript.

\section{REFERENCES}

1. An, Q., D. Buxton, A. Hendricks, L. Robinson, J. Shah, L. Lu, M. VeraGarcia, W. King, and D. M. Olive. 1995. Comparison of amplified Q $\beta$ replicase and PCR assays for detection of Mycobacterium tuberculosis. J. Clin. Microbiol. 33:860-867.

2. Barnard, G. F., M. Puder, N. A. Begum, and L. B. Chen. 1994. PCR product sequencing with $\left[\alpha-{ }^{33} \mathrm{P}\right]$ and $\left[\alpha-{ }^{32} \mathrm{P}\right] \mathrm{dATP}$. BioTechniques 16:572-573.

3. Barns, S. M., D. J. Lane, M. L. Sogin, C. Bibeau, and W. G. Weisburg. 1991 Evolutionary relationships among pathogenic Candida species and relatives. J. Bacteriol. 173:2250-2255.

4. Beck, K.-F., I. Stathopulos, M. G. Berninger, and M. Scheweizer. 1993 Overcoming GC compression in nucleotide sequencing. BioTechniques 14:375.

5. Böddinghaus, B., T. Rogall, T. Flohr, H. Blöcker, and E. C. Böttger. 1990 Detection and identification of mycobacteria by amplification of rRNA. J. Clin. Microbiol. 28:1751-1759.

6. Böttger, E. C. 1989. Rapid determination of bacterial ribosomal RNA sequences by direct sequencing of enzymatically amplified DNA. FEMS Microbiol. Lett. 65:171-176.

7. Butler, W. R., S. P. O'Conner, M. A. Yakrus, and W. M. Gross. 1994. Crossreactivity of genetic probe for detection of Mycobacterium tuberculosis with newly described species Mycobacterium celatum. J. Clin. Microbiol. 32:536-538.

8. Casanova, J.-L., C. Pannetier, C. Jaulin, and P. Kourilsky. 1990. Optimal conditions for directly sequencing double-stranded PCR products with Sequenase. Nucleic Acids Res. 18:4028.

9. Coyle, M. B., L. C. Carlson, C. K. Wallis, R. B. Leonard, V. A. Raisys, J. O. Kilburn, M. Samadpour, and E. C. Böttger. 1992. Laboratory aspects of Mycobacterium genavense, a proposed species isolated from AIDS patients. J. Clin. Microbiol. 30:3206-3212.

10. De Soete, G. 1983. A least squares algorithm for fitting additive trees to proximity data. Psychometrika 48:621-626.

11. Fichot, O., and M. Girard. 1990. An improved method for sequencing of RNA templates. Nucleic Acids Res. 18:6162.

12. Ford, E. G., S. J. Snead, J. Todd, and N. G. Warren. 1993. Strains of Mycobacterium terrae complex which react with DNA probes for $M$. tuberculosis complex. J. Clin. Microbiol. 31:2805-2806.

13. Frothingham, R., H. G. Hills, and K. H. Wilson. 1994. Extensive DNA sequence conservation throughout the Mycobacterium tuberculosis complex. J. Clin. Microbiol. 32:1639-1643.

14. Gaynor, C. D., R. A. Clark, F. P. Koontz, S. Emler, B. Hirschel, and L. S. Schlesinger. 1994. Disseminated Mycobacterium genavense infection in two patients with AIDS. Clin. Infect. Dis. 18:455-457.

15. Good, R. C. 1991. The genus Mycobacterium-medical, p. 1238-1270. In A. Balows, H. G. Trüper, M. Dworkin, W. Harder, and K.-H. Schleifer (ed.), The prokaryotes, 2nd ed., vol. II. Springer-Verlag, New York

16. Gutell, R. R., M. W. Gray, and M. N. Schnare. 1993. A compilation of large subunit (23S- and 23S-like) ribosomal RNA structures. Nucleic Acids Res. 21:3055-3074.

17. Gyllensten, U. B., and H. A. Erlich. 1988. Generation of single-stranded DNA by the polymerase chain reaction and its application to direct sequencing of the HLA-DQalpha locus. Proc. Natl. Acad. Sci. USA 85:7652-7656.

18. Hartmans, S., and J. A. M. De Bont. 1991. The genus Mycobacteriumnonmedical, p. 1214-1237. In A. Balows, H. G. Trüper, M. Dworkin, W. Harder, and K.-H. Schleifer (ed.), The prokaryotes, 2nd ed., vol. II. SpringerVerlag, New York.

19. Higuchi, R. G., and H. Ochman. 1989. Production of single-stranded DNA templates by exonuclease digestion following the polymerase chain reaction. Nucleic Acids Res. 17:5865.

20. Hughes, M. S., R. A. Skuce, L.-A. Veck, and S. D. Neill. 1993. Identification of mycobacteria from animals by restriction enzyme analysis and direct DNA cycle sequencing of polymerase chain reaction-amplified 16S rRNA gene sequences. J. Clin. Microbiol. 31:3216-3222.

21. Kirschner, P., A. Meier, and E. C. Böttger. 1993. Genotypic identification and detection of mycobacteria-facing novel and uncultured pathogens, $p$. 173-190. In D. H. Persing, T. F. Smith, F. C. Tenover, and T. J. White (ed.), Diagnostic molecular microbiology: principles and applications. American Society for Microbiology, Washington, D.C.

22. Lane, D. J. 1991. 16S/23S rRNA sequencing, p. 115-176. In E. Stackebrandt and M. Goodfellow (ed.), Nucleic acid techniques in bacterial systematics. J. Wiley \& Sons, New York.

23. Lane, D. J., B. Pace, G. J. Olsen, D. A. Stahl, M. L. Sogin, and N. R. Pace. 1985. Rapid determination of 16 S ribosomal RNA sequences for phylogenetic analyses. Proc. Natl. Acad. Sci. USA 82:6955-6959.

23a.Maidak, B. Personal communication.

24. Maidak, B. L., N. Larsen, M. J. McCaughey, R. Overbeek, G. J. Olsen, K. Fogel, J. Blandy, and C. R. Woese. 1994. The Ribosomal Database Project. Nucleic Acids Res. 22:3485-3487.

25. Mitchell, L. G., and C. R. Merill. 1989. Affinity generation of single-stranded DNA for dideoxy sequencing following the polymerase chain reaction. Anal. Biochem. 178:239-242.

26. Myers, T. W., and D. H. Gelfand. 1991. Reverse transcriptions and DNA amplification by a Thermus thermophilus DNA polymerase. Biochemistry 30:7661-7666.

27. O'Brien, D. P., D. Billadeau, and B. Van Ness. 1994. RT-PCR assay for detection of transcripts from very few cells using whole cell lysates. BioTechniques 16:586-590. 
28. Olsen, G. J. 1988. Phylogenetic analysis using ribosomal RNA. Methods Enzymol. 164:793-812

29. Pitulle, C., M. Dorsch, J. Kazda, J. Wolters, and E. Stackebrandt. 1992 Phylogeny of rapidly growing members of the genus Mycobacterium. Int. J. Syst. Bacteriol. 42:337-343.

30. Reynolds, T. R., S. R. B. Uliana, L. M. Floeter-Winter, and G. A. Buck. 1993 Optimization of coupled PCR amplification and cycle sequencing of cloned and genomic DNA. BioTechniques 15:462-467.

31. Rogall, T., J. Wolters, T. Flohr, and E. Böttger. 1990. Towards a phylogeny and definition of species at the molecular level within the genus Mycobacterium. Int. J. Syst. Bacteriol. 40:323-330.

32. Ruan, C. C., and C. W. Fuller. 1991. Using T7 gene 6 exonuclease to prepare single-stranded templates for sequencing. Comments U. S. Biochemical Corp. 18:1-8.

33. Ruano, G., and K. K. Kidd. 1991. Coupled amplification and sequencing of genomic DNA. Proc. Natl. Acad. Sci. USA 88:2815-2819.

34. Shinnick, T. M., and R. C. Good. 1994. Mycobacterial taxonomy. Eur. J. Clin. Microbiol. Infect. Dis. 13:884-901.

35. Stackebrandt, E., and B. M. Goebel. 1994. Taxonomic note: a place for
DNA-DNA reassociation and 16S rRNA sequence analysis in the present species definition in bacteriology. Int. J. Syst. Bacteriol. 44:846-849.

36. Stahl, D. A., and J. W. Urbance. 1990. The division between fast- and slow-growing species corresponds to natural relationships among the mycobacteria. J. Bacteriol. 172:116-124.

37. Telenti, A., F. Marchesi, M. Balz, F. Bally, E. C. Böttger, and T. Bodmer 1993. Rapid identification of mycobacteria to the species level by polymerase chain reaction and restriction enzyme analysis. J. Clin. Microbiol. 31:175-178.

38. Teske, A., B. Böddinghaus, T. Rogall, A. Ohrdorf, and E. C. Böttger. 1991. A general method for generation of taxon-specific DNA probes: application for the detection and identification of mycobacteria by amplification of rRNA followed by hybridization with specific oligonucleotides. Adv. Mol. Gen. 3:265-276.

39. Walther, W., U. Stein, and C. Eder, 1994. RNA analysis using miniprep RNA in reverse transcription PCR. BioTechniques 17:674-675.

40. Wang, R.-F., W. W. Cao, and M. F. Slavik. 1991. Comparison and modification of rRNA sequencing methods. BioTechniques 11:438-439.

41. Weisburg, W. G., S. M. Barns, D. A. Pelletier, and D. J. Lane. 1991. 16S ribosomal DNA amplification for phylogenetic study. J. Bacteriol. 173:697-703. 